\title{
Title
}

\section{The potential of SLC6A4 gene methylation analysis for the diagnosis and treatment of major depression}

\section{Author}

Satoshi Okada ${ }^{1}$, Shigeru Morinobu ${ }^{1 *}$, Manabu Fuchikami ${ }^{1}$, Masahiro Segawa ${ }^{1}$, Kana

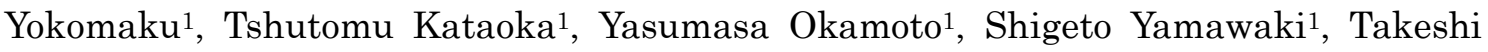
Inoue $^{2}$, Ichiro Kusumi², Tsukasa Koyama², Kounosuke Tsuchiyama ${ }^{3}$, Takeshi Terao ${ }^{3}$, Masaru Mimura ${ }^{4}$

$(*$ : corresponding author)

\section{Address}

1:Department of Psychiatry and Neurosciences,

Applied Life Sciences Institute of Biomedical \& Health Sciences,

Hiroshima University, 1-2-3 Kasumi, Minami-ku, Hiroshima, Hiroshima, Japan

TEL: +81-82-257-5555; FAX: +81-82-257-5209

*:e-mail: smorinob@kochi-u.ac.jp

2:Department of Psychiatry

Hokkaido University, Sapporo, Hokkaido, Japan

3:Department of Psychiatry

Oita University, Yufu, Oita, Japan

4:Department of Psychiatry

Showa University, Shinagawa. Tokyo, Japan

\section{Key words}

Major depression; DNA methylation; Serotonin transporter; Serotonin transporter-linked polymorphic region; antidepressant; therapeutic response 


\begin{abstract}
We examined the utility of DNA methylation profiles at the CpG island of SLC6A4 (DMS) as a diagnostic biomarker for major depression (MD). In addition, the relationship between DMS and the serotonin transporter gene-linked polymorphic region (5-HTTLPR) allele, the severity of symptoms, number of early adversities, and therapeutic responses to antidepressants were examined. Genomic DNA was extracted from peripheral blood of Japanese healthy controls and patients with MD before and after treatment. DMS was analyzed using a MassARRAY Compact System. The severity of depression was evaluated using the Hamilton Rating Scale for Depression, and early adversity was evaluated using the Early Trauma Inventory. We were unable to distinguish between and healthy controls, or between unmedicated patients and medicated patients using DMS. The 5-HTTLPR allele had no significant effect on DMS. The methylation rates for several CpGs differed significantly after treatment. Notably, the methylation rate of $\mathrm{CpG} 3$ in patients with better therapeutic responses was significantly higher than that in patients with poorer responses. Although further studies examining the function of specific CpG units of SLC6A4 are required, these results suggest that the pre-treatment methylation rate of SLC6A4 is associated with therapeutic responses to antidepressants in unmedicated patients with MD.
\end{abstract}




\section{Introduction}

Major depression (MD) is a common illness worldwide and was the second leading contributor to global disease burden in 2010 (Vos et al., 2012). Since long-lasting emotional and psychomotor disturbances due to MD can induce functional difficulties at work, school, or home, MD is predicted to become the second-leading cause of disability-adjusted life years in 2020 based on the systematic analyses of population health data (Murray and Lopez, 1997). In addition, MD is a leading cause of suicide and is responsible for 1 million suicide-related deaths every year (WHO, 2012). In this context, early diagnosis and intervention are necessary to prevent worsening of MD and MD-related suicide attempts. However, the diagnostic system for MD, which relies on subjective assessment of patient symptoms using, for example, the Diagnostic and Statistical Manual of Mental Disorders Fourth Edition (DSM-IV) or the International Classification of Diseases Tenth Edition (ICD-10) rather than an objective laboratory test, may be associated with misdiagnoses, poor outcomes in the treatment of $\mathrm{MD}$, and development of refractory depression.

To establish objective diagnostic biomarkers for MD, numerous approaches have been undertaken. For example, Carroll and colleagues $(1981 ; 1982)$ proposed dexamethasone suppression test (DST) results as a biomarker for the diagnosis of melancholia based on dysregulation of the hypothalamo-pituitary-adrenal (HPA) axis in MD, but a major drawback of DST was its modest sensitivity. Subsequently, a refined laboratory test, the combined dexamethasone/corticotrophin-releasing hormone (DEX/CRH) test, was developed (Heuser et al., 1994), although the sensitivity for detection of MD was only $80 \%$ at best (Mossner et al., 2007).

We recently proposed that the methylation profile of the promoter region of exon I of 
the brain-derived neurotrophic factor (BDNF) gene could serve as a valuable diagnostic biomarker for MD (Fuchikami et al., 2011). It is well known that the concordance rate for MD in monozygotic twins is almost 40\% (Fu et al., 2002; McGuffin et al., 1996; Sullivan et al., 2000). The heritability of MD is lower than that of bipolar disorder or schizophrenia (Goodwin and Jamison, 2007; Moldin and Gottesman, 1997). These epidemiological studies suggest that gene-environment interactions play a pivotal role in the etiology of MD. With regard to this interaction, growing evidence indicates that the regulation of DNA methylation in response to environmental stimuli plays an important role in the development of stress vulnerability, predisposing to MD under stressful situations (McGowan et al., 2009; Weaver et al., 2004; Zhang et al., 2013). Thus, it is plausible that epigenetic factors could be used for the development of a more sophisticated diagnosis system for MD.

The serotonin transporter (5-HTT) is a major target of antidepressants and the activity of 5-HTT is inhibited by different types of antidepressants. In vivo neuroimaging and postmortem histochemical studies have shown decreased 5-HTT binding density mainly in the prefrontal cortex of patients with MD (Stockmeier, 2003). Whereas a recent in vivo neuroimaging study using positron emission tomography (PET) demonstrated increased 5-HTT binding in the thalamus, insula, and striatum of patients with MD (Cannon et al., 2007), another PET study reported lower 5-HTT binding in the midbrain of patients with MD, particularly those who were unmedicated (Parsey et al., 2006). Based on these findings, it is conceivable that altered 5-HTT function in the brain plays an important role in the pathophysiology of depression.

Furthermore, it is well known that the short $(s)$ allele of the 5-HTT gene-linked polymorphic region (5-HTTLPR: 43-bp deletion or insertion in the promoter of exon I) is 
associated with anxiety-related personality traits (Lesch et al., 1996), and that this polymorphism is associated with decreased expression of the 5-HTT gene in the 5-HTTLPR $s$ allele (Bradley et al., 2005). The 5-HTTLPR $s$ allele has been reported to be associated with an increased risk of developing depression under stress (Karg et al., 2011).

A recent meta-analysis revealed a significant association between 5-HTTLPR and the clinical response to selective serotonin reuptake inhibitor (SSRI) treatment in terms of both the remission rate and response rate in depressed patients. This suggests that 5-HTTLPR could be a predictor of the response to SSRIs (Serretti et al., 2007). Together, these observations indicate that individual differences in the transcriptional activity of 5-HTT might be involved in the pathophysiology of MD and the response to antidepressant treatment.

With regard to the regulation of 5-HTT expression, the methylation rate of the CpG island at the 5' region of the SLC6A4 gene have been reported to be associated with the levels of 5-HTT mRNA in human lymphoblast cells (Philibert et al., 2007). In addition, Wang and associates (Wang et al., 2012) reported that in vitro methylation in the promoter of exon I of the SLC6A4 gene in a luciferase-reporter construct suppressed its transcriptional activity. Furthermore, the possibility of a joint effect of 5HTT methylation and 5HTTLPR $s$ allele carriage on the risk for depression was reported recently (Olsson et al., 2010). These findings suggest that the methylation status of the promoter of exon I of the SLC6A4 gene alters transcription of the SLC6A4 gene, and subsequently leads to the occurrence of MD.

It has also been reported that early adversity is associated with increased prevalence, earlier onset (Widom et al., 2007) or severity of symptoms, treatment resistance of MD 
(Tunnard et al., 2013; Widom et al., 2007), and elevated DNA methylation across the SLC6A4 gene promoter in subjects without MD as well as in those without psychiatric disorders (Beach et al., 2010; 2011). Furthermore, increased DNA methylation of the SLC6A4 gene has been reported to be associated with bullying victimization in childhood (Ouellet-Morin et al., 2013).

In the present study, we assessed the degree of symptoms and early adversity of patients with $\mathrm{MD}$, analyzed DNA methylation rates of the $\mathrm{CpG}$ island in the promoter of exon I of the SLC6A4 gene (DMR), and conducted genotyping of 5-HTTLPR using genomic DNA from the peripheral blood of patients with MD or healthy controls.

First, we examined whether the profile of the SLC6A4 gene was an appropriate diagnostic biomarker for MD. Next, we analyzed the effect of genotype on DMR, the relationship between DMR and the severity of symptoms, and the association between DMR and the number of early adversities. Finally, the effect of antidepressant treatment on DMR and the relationship between DMR and response rates was analyzed by comparing data sets from patients with MD before and after antidepressant treatment to evaluate the potential of DMR as a predictor of the treatment response.

\section{Materials and Methods}

\section{Subjects}

Fifty patients with MD and 50 healthy controls participated in this study. Demographic characteristics of the participants are shown in Table 1. All participants were Japanese. All patients were diagnosed by trained psychiatrists according to DSM-IV criteria (American Psychiatric Association, 1994), on the basis of unstructured interviews, information from medical records, and the use of a structured clinical 
interview (the Japanese version of the Mini-International Neuropsychiatric Interview) by a research psychiatrist. The criteria for the selection of samples in this study was as follows: (1) median age $(21 \sim 62$ years old $),(2)$ distribution of sex was almost equal among groups, (3) severity of symptoms were moderate so as to be able to give written informed consent, (4) all patients did not have treatment history or previous depressed episodes. The severity of depression was evaluated using the Hamilton Rating Scale for Depression (HAM-D; Hamilton. 1967; Cusin et al., 2009) and early adversity was evaluated using the Early Trauma Inventory Self Report-Short Form (ETISR-SF; Bremner JD et al., 2000; 2007).

None of the patients had current or past diagnoses of substance-related disorders or physical diagnoses. Healthy controls were recruited by advertisement. They had no current or past psychiatric or physical diagnoses, and they had no first-degree relatives with MD. Blood samples were collected at Hiroshima University Hospital, Hokkaido University Hospital, Oita University Hospital and Showa University Hospital. Medical treatment was initiated in 50 patients; 40 patients were available for a follow-up interview 6 weeks later, at which time additional blood samples were collected.

This study was approved by the respective ethics committees of Hiroshima University School of Medicine, Hokkaido University School of Medicine, Oita University School of Medicine, and Showa University School of Medicine. All subjects received a description of the study and gave written informed consent.

\section{Selection of genomic regions of the SLC6A4 gene for DNA methylation analysis}

We chose the $\mathrm{CpG}$ island of the SLC6A4 gene as a target for analysis. The target region around the SLC6A4 gene was selected based on a previous report (Olsson et al., 2010). 
The sequence of the CpG island was identified using the UCSC genome database (http://genome.ucsc.edu/), (chr 17: 28562388 - 28563186). PCR primers were designed using Epidesigner software (http://www.epidesigner.com/). The schema for the target region used for analysis and the primers used for PCR are shown in Figure 1.

\section{Genotyping to generate S- and L- fragments}

The sequence of 5HTTLPR was identified using the UCSC genome database (chr 17: 28564123 - 28564473) (Figure 1). PCR primers were designed using Primer 3 software (http://frodo.wi.mit.edu/primer3/input.htm). PCR was performed in a total volume of 5 $\mu \mathrm{L}$ solution containing $10 \mathrm{ng}$ DNA, $2 \times \mathrm{Gflex}^{\circledR}$ PCR Buffer, $1 \mathrm{mM} \mathrm{MgCl} 2,200 \mu \mathrm{M}$ dNTPs, $0.2 \mu \mathrm{M}$ of each primer, and $0.125 \mathrm{U}$ of Tks Gflex ${ }^{\circledR}$ DNA polymerase (Takara, Tokyo, Japan) for 30 cycles $\left(98^{\circ} \mathrm{C}\right.$ for $10 \mathrm{~s}, 60^{\circ} \mathrm{C}$ for $15 \mathrm{~s}$, and $68^{\circ} \mathrm{C}$ for $\left.30 \mathrm{~s}\right)$. The PCR products were then analyzed by $2 \%$ agarose gel stained with ethidium bromide. The distributions of genotypes in controls and patients with MD were in Hardy-Weinberg equilibrium (Healthy controls: $\mathrm{X}^{2}=0$; Patients: $\left.\mathrm{X}^{2}=1.84\right)$ (Table 1).

\section{DNA methylation analysis by MassARRAY}

All samples were collected between 11:00 AM and 1:00 PM, prior to the participants' lunch. Blood samples $(5 \mathrm{~mL})$ were collected and placed in vacuum tubes containing heparin sodium and stored at $-80{ }^{\circ} \mathrm{C}$. Genomic DNA was isolated using DNeasy ${ }^{\circledR}$ Blood and Tissue Kits (Qiagen, Hilden, Germany). Genomic DNA (1 $\mu \mathrm{g})$ was converted with sodium bisulfite using EZ DNA methylation kits (Zymo Research, Orange, CA). The concentration of bisulfite-converted DNA was measured using an ND-1000 spectrophotometer (NanoDrop Technologies, Inc., Wilmington, DE, USA); 10 ng of 
converted DNA was used for PCR. PCR was performed in a total volume of $5 \mu \mathrm{L}$ containing $1 \mu \mathrm{M}$ of each primer, $200 \mu \mathrm{M}$ dNTP, $0.2 \mathrm{U}$ HotStar Taq DNA polymerase (Qiagen), $2 \mathrm{mM} \mathrm{MgCl}$, and 10× PCR buffer (Sequenom, Inc., San Diego, CA, USA). One of two primers in the PCR amplification of the target regions was tagged with a T7 promoter sequence: CAGTAATACGACTCACTATAGGGAGAAGGCT. This included a GGG transcription start and an 8-bp insert (AGAAGGCT) on the 5' end. The reaction mixture was preactivated for 4 min at $95^{\circ} \mathrm{C}$. DNA was amplified for 45 cycles $\left(95^{\circ} \mathrm{C}\right.$ for $20 \mathrm{~s}, 56^{\circ} \mathrm{C}$ for $30 \mathrm{~s}$ and $72{ }^{\circ} \mathrm{C}$ for $60 \mathrm{~s}$ ) and the reaction was then continued at $72{ }^{\circ} \mathrm{C}$ for 3 $\min$.

Unincorporated dNTPs were dephosphorylated by adding $1.7 \mu \mathrm{L}$ DNase free water and $0.3 \mathrm{U}$ shrimp alkaline phosphatase (SAP) (Sequenom). The reaction was incubated at $37{ }^{\circ} \mathrm{C}$ for $20 \mathrm{~min}$ and $\mathrm{SAP}$ was inactivated for $5 \mathrm{~min}$ at $85^{\circ} \mathrm{C}$. Subsequently, PCR products $(2 \mu \mathrm{L})$ were incubated for $3 \mathrm{~h}$ at $37{ }^{\circ} \mathrm{C}$ with $5 \mu \mathrm{L}$ of Transcleave mix (Sequenom) for concurrent in vitro transcription and base-specific cleavage.

The resultant 10- to $20^{-n L}$ products were spotted onto silicon matrix-preloaded chips (SpectroCHIP; Sequenom) using a MassARRAY nanodispenser (Sequenom), and analyzed using a MassARRAY Compact System matrix-assisted laser desorption/ionization-time-of-flight mass spectrometer (MALDI-TOF-MS) (Sequenom). The spectra's methylation ratios were calculated using EpiTYPER software v1.0 (Sequenom). Triplicate independent analyses from bisulfite-converted DNA samples were undertaken. The method yielded quantitative results for each of the sequence-defined analytic units referred to as CpG units. These methods divided 81 CpG sites in the $\mathrm{CpG}$ island into $41 \mathrm{CpG}$ units.

After obtaining the data, initial quality control was performed as follows. Poor-quality 
and non-valuable data for the quantitative methylation of each CpG unit measured by MALDI-TOF-MS were excluded. Ten CpG units were excluded because their molecular weights were outside the measurable range. In subsequent analyses, data for $2 \mathrm{CpG}$ units were excluded as they were less than $80 \%$ of all samples. Data were available for 29 of $41 \mathrm{CpG}$ units in the CpG island and for all samples.

\section{Statistical analysis}

For analysis of the DNA methylation profile, measurements after QC were combined in a data matrix, which was used in a 2-dimensional hierarchical clustering analysis with the "R" software package for statistical computing (available at CRAN, http://cran.r-project.org/). Hierarchical clustering analyses were performed using hclust in the $\mathrm{R}$ cluster package, with Euclidean metric and complete linkage. Samples with closer methylation patterns were closely clustered. The Mann Whitney $U$ test was used to examine differences in the methylation rates of each $\mathrm{CpG}$ unit between healthy controls and patients. The Wilcoxon signed-rank test was used to examine differences in the methylation rates of each $\mathrm{CpG}$ unit between patients before and after 6 weeks of antidepressant treatment. The significance of each statistical test by Bonferroni correction was set at $\mathrm{P}<0.0017$.

The Spearman rank correlation test was used to examine the correlation between the methylation rate of each CpG unit and total HAM-D scores, total ETISR-SF scores, and improvement ratio (IR: (HAM-D before treatment - HAM-D after 6 weeks treatment)/HAM-D before treatment) in patients. The T-test was used for subsequent analyses of significance. Significance was set at $\mathrm{P}<0.05$. 


\section{Results}

DNA methylation profiles at in the CpG island of the SLC6A4 gene among all participants.

Two-way hierarchical clustering analysis of DMR was undertaken to classify samples and $\mathrm{CpG}$ units into clusters according to their similarity, and a dendrogram was used to visualize the results. DNA methylation profiles at the CpG island in the SLC6A4 gene of all subjects are shown in heat map format (Supplemental figure 1). At any height of the dendrogram acquired from clustering analysis, it was impossible to distinguish between unmedicated patients and healthy controls (Supplemental figure 1).

Next, we compared the methylation rates of each CpG unit between unmedicated patients and healthy controls. There was no significant difference between unmedicated patients and healthy controls at any CpG unit (Table 2).

\section{The influence of SLC6A4 genotyping for classifying participants.}

SLC6A4 genotyping analysis demonstrated that 18 healthy controls had $1 / 1$ or $1 / s$ alleles (an 1 allele) and 32 healthy controls had $s / s$ alleles. Similarly, while 16 patients had an $I$ allele, 34 patients had $s / s$ alleles (Table 1). Two-way hierarchical clustering analysis of DNA methylation profiles could not distinguish samples into any groups associated with diagnosis and/or allele (all participants with an lallele vs those with $s / s$ alleles, healthy controls with an 1 allele vs those with $s / s$ alleles, or patients with an $I$ allele vs those with $s / s$ alleles) (Supplemental figure 2).

We next compared the methylation rates of each $\mathrm{CpG}$ unit among all participants by two-factor ANOVA using genotypes ( 1 allele and $s / s$ alleles) and diagnoses (healthy controls and patients) as fixed factors. Significance after Bonferroni correction was set 
at $\mathrm{P}<0.0017$. There was no significant effect of genotype on diagnosis. This result indicated that 5-HTTLPR did not affect DMR.

Correlations between DMR and total HAM-D scores, and DMR and total ETISR-SF scores

Next, we examined correlations between the methylation rates for each $\mathrm{CpG}$ unit of the $\mathrm{CpG}$ island of the SLC6A4 gene and the severity of depressive symptoms as well as the number of early adversities (Table 3). Regarding the severity of MD, there was a significant positive correlation between the methylation rate for $\mathrm{CpG} 76$ and total HAM-D score $(|\mathrm{r}|=0.30, \mathrm{P}=0.03$, power=0.57). Regarding early adversity, while there was a significant negative correlation between the methylation rate of $\mathrm{CpG} 3$ and total ETISR-SF score $(|\mathrm{r}|=0.32, \mathrm{P}=0.02$, power $=0.63)$, a significant positive correlation was found between the methylation rate for CpG 76 and total ETISR-SF score $(|\mathrm{r}|=0.32$, $\mathrm{P}=0.02$, power $=0.63)$.

DNA methylation profiles in the CpG island of the SLC6A4 gene before and after treatment (unmedicated vs medicated patients)

To evaluate the effect of 6-week antidepressant treatment on DNA methylation profiles in the CpG island of the SLC6A4 gene, two-way hierarchical clustering analysis was performed (Supplemental figure 3). At any height of the dendrogram acquired from clustering analysis, it was impossible to distinguish between unmedicated patients and medicated patients (Supplemental figure 3). We also compared the methylation rates for each CpG unit between unmedicated and medicated patients (Table 2). A significant difference in the methylation rates for $\mathrm{CpG} 3(|\mathrm{Z}|=3.47, \mathrm{P}=0.0004$, power=0.77) was 
found between unmedicated and medicated patients.

\section{Relationship between DMR and improvement ratios in response to 6-week antidepressant treatment}

To evaluate the potential of DMR as a predictor of treatment response, we analyzed the relationship between pre-treatment methylation rates for each $\mathrm{CpG}$ unit and therapeutic responses. The therapeutic responses to antidepressants (paroxetine, fluvoxamine, or milnaciprane) for 6 weeks were defined based on IRs. Correlation analysis was conducted using the IR and the pre-treatment methylation rates for each CpG unit. The pre-treatment methylation rate of CpG 3 showed a significant positive correlation with IRs in MD patients $(|\mathrm{r}|=0.36, \mathrm{P}=0.02$, power $=0.64$, Table 3$)$.

Two-way hierarchical clustering analysis was performed using samples from patients with an IR of $50 \%$ or more, and patients with an IR of less than 50\% (Supplemental figure 4). At any height of the dendrogram acquired from clustering analysis, it was impossible to classify patients into 2 groups in agreement with the IRs (Supplemental figure 4).

Subsequently, we compared the pre-treatment methylation rate of $\mathrm{CpG} 3$ between these 2 groups because it was only changed significantly after antidepressant treatment. The pre-treatment methylation rate of CpG 3 correlated with IRs, and a significant difference was observed $(|\mathrm{U}|=1.98, \mathrm{P}=0.047$, power $=0.33)$.

We determined the relationship between IR and the methylation change of CpG 3 before and after treatment. However, there was no significant correlation (data not shown). Furthermore, we did not identify a significant correlation between IR and ETI (data not shown). 


\section{Discussion}

In the present study, we could not distinguish between healthy controls and unmedicated patients with MD, or between unmedicated and medicated patients with MD based on the results of two-dimensional hierarchical clustering analysis using DNA methylation rates of $\mathrm{CpG}$ units in the $\mathrm{CpG}$ island of the SLC6A4 gene. Two-way hierarchical clustering analysis and two-factor ANOVA using genotypes ( $I$ allele and $s / s$ alleles) and diagnoses (healthy controls and patients with MD) as fixed factors revealed that 5-HTTLPR itself did not affect DMR. Comparisons of DNA methylation rates for each $\mathrm{CpG}$ unit indicated that analysis of the pre-treatment methylation rate of CpG 3 might be useful for determining the therapeutic responses to antidepressants. In addition, correlation analysis using the DNA methylation rate for each $\mathrm{CpG}$ unit revealed that DNA methylation rates of several CpG sites were associated with characteristics of patients with $\mathrm{MD}$ : $\mathrm{CpG} 3$ and $\mathrm{CpG} 76$ for early adversity in MD patients, and CpG 76 for severity of MD symptoms. We also analyzed the data with respect to the therapeutic response. Although we could not distinguish between patients with high and low therapeutic responses by clustering analysis using all the DNA methylation rates, correlation analysis revealed the pre-treatment DNA methylation rate of $\mathrm{CpG} 3$ correlated with the therapeutic response and an individual comparison of CpG 3 revealed that the DNA methylation rate of CpG 3 was significantly different.

Many epigenetic changes are reversible in response to both external and internal stimuli, indicating a mechanism for interactions of the genome with the environment. Notably, various factors associated with complex diseases, for example nutrition, chemical exposure, and psychosocial stress, have been correlated with epigenetic changes, particularly DNA methylation (Feil and Fraga, 2011). Such findings integrate 
epigenetic research with population-based epidemiological research investigating not only diagnosis methods (Mill and Heijmans, 2013), but also drug responses and the effect of therapeutic drugs (Duarte, 2013). We recently reported that classification based on DNA methylation profiles of the CpG island in the promoter of exon I of the BDNF gene could be a valuable diagnostic biomarker for MD (Fuchikami et al., 2011). In addition, D'Addario and colleagues (2013) reported the possible association of changes in DNA methylation of the BDNF promoter with the onset of and/or susceptibility to bipolar disorder, or with mood-stabilizing compounds and antidepressants. In contrast with results of two previous studies, the present study suggested possible associations of DNA methylation of the SLC6A4 gene with the diagnosis of MD, antidepressant treatment, early adversity, and therapeutic responses only when analyses based on data for each specific CpG unit were used, but not when using analyses of all DMR.

In general, an association between DNA methylation and transcriptional activity is considered an important marker of functional relevance (Stranger BE et al., 2007; Dimas et al., 2009).

With regard to the SLC6A4 gene, Philibert and colleagues reported a significant association between SLC6A4 promoter methylation levels and mRNA levels using peripheral blood from patients with depression (Philibert et al., 2007). However, it is becoming evident that the relationship between DNA methylation and gene expression is not always tightly linked. In terms of biomarker identification, the fact that methylation is closely associated with a specific pathological condition is thought to be important, even if methylation does not induce gene silencing (Ushijima, 2005). 5HTT is associated with pathological conditions and the treatment of MD (Lesch and Gutknecht., 2005; Murphy et al., 2009). In this context, the present study only analyzed DNA 
methylation but not gene expression levels. Future studies examining DNA methylation in the promoter of the SLC6A4 gene together with gene expression will be needed to reveal the functional relevance of DNA methylation of this gene in the pathophysiology of MD.

Thus, although the biological significance of changes in DNA methylation rates for specific CpG units of the SLC6A4 gene is not known, the results of the present study suggest that such information may provide important clinical information regarding MD.

Previous reports described the possibility of a joint effect of 5HTT methylation and 5HTTLPR $s$ allele carriage on the risk for depression (Olsson et al., 2010) and the effect of CpG islands on DNA methylation by distantly-located SNPs in a fraction of genes (Bell et al., 2011; Soto-Ramirez et al., 2013). Therefore, we evaluated the influence of the 5HTTLPR allele on DMR. Contrary to the results of Olsson and coworkers (2010), we found no significant effect on the DNA methylation rates of any CpG unit by genotype. The discrepancy between these studies may be attributed to differences in the tissues (buccal cells vs blood cells) and analytic methods used (Olsson divided the CpG island of the SLC6A4 gene into sub-regions according to co-variation in methylation levels between CpG units).

Changes in the DNA methylation rate of CpG 3 were the most intriguing finding of this study. The DNA methylation rate of CpG 3 correlated negatively with ETISR-SF, and was significantly changed after antidepressant treatment, but correlated positively with therapeutic responses. Several studies have reported that increased DNA methylation of several CpG units within the SLC6A4 gene was associated with early adversity (Ouellet-Morin et al., 2013) and antidepressant treatment (Kang et al., 2013). Although 
those studies investigated different and smaller regions of the SLC6A4 gene for DNA methylation analyses compared with the present study, they suggested the versatility of DNA methylation of specific CpG units of the SLC6A4 gene induced by environmental factors. In addition, the high prevalence of early adversity in treatment-resistant depressed patients was reported recently (Tunnard et al., 2013). Although the function of CpG 3 methylation of the SLC6A4 gene is unknown, the sequence of changes in the methylation rates at this region (negative correlation with early adversity and positive correlation with response rates) indicates the possible involvement of this factor in the mechanism of resistance to antidepressant treatment.

In summary, analyses using DNA methylation rates for specific CpG units of the SLC6A4 gene, but not analyses based on DNA methylation rates of all CpG units, may be a potential biomarker for the diagnosis, severity of symptoms, early adversity, and history of antidepressant treatment in patients with MD. Notably, the pre-treatment DNA methylation rate for CpG 3 may be associated with antidepressant treatment responses. In addition, the DNA methylation rate for $\mathrm{CpG} 3$ indicated possible involvement in the mechanism of treatment resistance associated with early adversity. Further studies examining the function of these CpG units will help to establish more sophisticated methods for the diagnosis and treatment of MD. 


\section{References}

Beach SR, Brody GH, Todorov AA, Gunter TD, Philibert RA. Methylation at SLC6A4 is linked to family history of child abuse: an examination of the Iowa Adoptee sample. Am J Med Genet B Neuropsychiatr Genet 2010; 153B: 710-713.

Beach SR, Brody GH, Todorov AA, Gunter TD, Philibert RA. Methylation at 5HTT mediates the impact of child sex abuse on women's antisocial behavior: an examination of the Iowa adoptee sample. Psychosom Med 2011; 73: 83-87.

Bell JT, Pai AA, Pickrell JK, Gaffney DJ, Pique-Regi R, Degner JF, Gilad Y, Pritchard JK. DNA methylation patterns associate with genetic and gene expression variation in HapMap cell lines. Genome Biol 2011; 12: R10.

Bradley SL, Dodelzon K, Sandhu HK, Philibert RA. Relationship of serotonin transporter gene polymorphisms and haplotypes to mRNA transcription. Am J Med Genet B Neuropsychiatr Genet 2005; 136B: 58-61.

Bremner JD, Bolus R, Mayer EA. Psychometric properties of the Early Trauma Inventory-Self Report. J Nerv Ment Dis. 2007; 195(3) 211-218. doi:10.1097/01.nmd.0000243824.84651.6c.

Bremner JD, Vermetten E, Mazure CM. Development and preliminary psychometric properties of an instrument for the measurement of childhood trauma: the Early Trauma Inventory. Depress Anxiety 2000; 12(1): 1-12.

Cannon DM, Ichise M, Rollis D, Klaver JM, Gandhi SK, Charney DS, Manji HK, Drevets WC. Elevated serotonin transporter binding in major depressive disorder assessed using positron emission tomography and [11C]DASB; comparison with bipolar disorder. Biol Psychiatry 2007; 62: 870-877. 
Carroll BJ. The dexamethasone suppression test for melancholia. Br J Psychiatry 1982; 140: $292-304$.

Carroll BJ, Feinberg M, Greden JF, Tarika J, Albala AA, Haskett RF, James NM, Kronfol Z, Lohr N, Steiner M, de Vigne JP, Young E. A specific laboratory test for the diagnosis of melancholia. Standardization, validation, and clinical utility. Arch Gen Psychiatry 1981; 38: 15-22.

Cusin C, yang H, Albert Y, Fava M. Rating scales for depression. Handbook of Clinical Rating Scales and Assessment in Psychiatry and Mental health. Edited by Baer L, Blais MA. Humana Press, a part of Springer Science Business Media 2009. Doi:10.1007/978-1-59745-387-5_2.

D'Addario C, Dell'Osso B, Galimberti D, Palazzo MC, Benatti B, Di Francesco A, Scarpini E, Altamura AC, Maccarrone M. Epigenetic modulation of BDNF gene in patients with major depressive disorder. Biol Psychiatry 2013; 73: e6-7.

Dimas AS, Deutsch S, Stranger BE, Montgomery SB, Borel C, Attar-Cohen H, Ingle C, Beazley C, Gutierrez Arcelus M, Sekowska M, Gagnebin M, Nisbett J, Deloukas P, Dermitzakis ET, Antonarakis SE. Common regulatory variation impacts gene expression in a cell type-dependent manner. Science 2009, 325: 1246-1250.

Duarte JD. Epigenetics Primer: Why the Clinician Should Care About Epigenetics.Pharmacotherapy 2013; doi:10.1002/phar. 1325.

Feil R, Fraga MF. Epigenetics and the environment: emerging patterns and implications. Nat Rev Genet 2011; 13: 97-109.

Fu Q, Heath AC, Bucholz KK, Nelson E, Goldberg J, Lyons MJ, True WR, Jacob T, Tsuang MT, Eisen SA. Shared genetic risk of major depression, alcohol dependence, and marijuana dependence: contribution of antisocial personality 
disorder in men. Arch Gen Psychiatry 2002; 59: 1125-1132.

Fuchikami M, Morinobu S, Segawa M, Okamoto Y, Yamawaki S, Ozaki N, Inoue T, Kusumi I, Koyama T, Tsuchiyama K, Terao T. DNA methylation profiles of the brain-derived neurotrophic factor (BDNF) gene as a potent diagnostic biomarker in major depression. PLoS One 2011; 6: e23881.

Goodwin FK, Jamison KR. Manic-depressive illness : Bipolar disorders and recurrent depression. Oxford Universiy Press. Second Edition 2007

Hamilton M. Development of a rating scale for primary depressive illness. British Journal of Social and Clinical Psychology 1967; 6(4): 278-296. Doi:10.1111/j.2044-8260.1967.tb00530.x.

Heuser I, Yassouridis A, Holsboer F. The combined dexamethasone/CRH test: a refined laboratory test for psychiatric disorders. J Psychiatr Res 1994; 28: 341-356.

Kang HJ, Kim JM, Stewart R, Kim SY, Bae KY, Kim SW, Shin IS, Shin MG, Yoon JS. Association of SLC6A4 methylation with early adversity, characteristics and outcomes in depression. Prog Neuropsychopharmacol Biol Psychiatry 2013; 44: $23-28$.

Karg K, Burmeister M, Shedden K, Sen S. The serotonin transporter promoter variant (5-HTTLPR), stress, and depression meta-analysis revisited: evidence of genetic moderation. Arch Gen Psychiatry 2011; 68: 444-454.

Lesch KP, Bengel D, Heils A, Sabol SZ, Greenberg BD, Petri S, Benjamin J, Muller CR, Hamer DH, Murphy DL. Association of anxiety-related traits with a polymorphism in the serotonin transporter gene regulatory region. Science 1996; 274: $1527-1531$.

Lesch KP, Gutknecht L. Pharmacogenetics of the serotonin transporter. Prog 
Neuropsychopharmacol Biol Psychiatry 2005; 29: 1062-1073.

McGowan PO, Sasaki A, D'Alessio AC, Dymov S, Labonte B, Szyf M, Turecki G, Meaney MJ. Epigenetic regulation of the glucocorticoid receptor in human brain associates with childhood abuse. Nat Neurosci 2009; 12: 342-348.

McGuffin P, Katz R, Watkins S, Rutherford J. A hospital-based twin register of the heritability of DSM-IV unipolar depression. Arch Gen Psychiatry 1996; 53: 129-136.

Mill J, Heijmans BT. From promises to practical strategies in epigenetic epidemiology. Nat Rev Genet 2013; 14: 585-594.

Moldin SO, Gottesman, II. At issue: genes, experience, and chance in schizophrenia--positioning for the 21st century. Schizophr Bull 1997; 23: $547-561$.

Mossner R, Mikova O, Koutsilieri E, Saoud M, Ehlis AC, Muller N, Fallgatter AJ, Riederer P. Consensus paper of the WFSBP Task Force on Biological Markers: biological markers in depression. World J Biol Psychiatry 2007; 8: 141-174.

Murphy DL, Fox MA, Timpano KR, Moya PR, Ren-Patterson R, Andrews AM, Holmes A, Lesch KP, Wendland JR. How the serotonin story is being rewritten by new gene-based discoveries principally related to SLC6A4, the serotonin transporter gene, which functions to influence all cellular serotonin systems. Neuropharmacology. $\quad 2008 ; \quad 55(6): \quad 932-960 . \quad$ doi: 10.1016/j.neuropharm.2008.08.034.

Murray CJ, Lopez AD. Alternative projections of mortality and disability by cause 1990-2020: Global Burden of Disease Study. Lancet 1997; 349: 1498-1504.

Olsson CA, Foley DL, Parkinson-Bates M, Byrnes G, McKenzie M, Patton GC, Morley R, 
Anney RJ, Craig JM, Saffery R. Prospects for epigenetic research within cohort studies of psychological disorder: a pilot investigation of a peripheral cell marker of epigenetic risk for depression. Biol Psychol 2010; 83: 159-165.

Ouellet-Morin I, Wong CC, Danese A, Pariante CM, Papadopoulos AS, Mill J, Arseneault L. Increased serotonin transporter gene (SERT) DNA methylation is associated with bullying victimization and blunted cortisol response to stress in childhood: a longitudinal study of discordant monozygotic twins. Psychol Med 2013; 43: 1813-1823.

Parsey RV, Hastings RS, Oquendo MA, Huang YY, Simpson N, Arcement J, Huang Y, Ogden RT, Van Heertum RL, Arango V, Mann JJ. Lower serotonin transporter binding potential in the human brain during major depressive episodes. Am J Psychiatry 2006; 163: 52-58.

Philibert R, Madan A, Andersen A, Cadoret R, Packer H, Sandhu H. Serotonin transporter mRNA levels are associated with the methylation of an upstream CpG island. Am J Med Genet B Neuropsychiatr Genet 2007; 144B: 101-105.

Serretti A, Kato M, De Ronchi D, Kinoshita T. Meta-analysis of serotonin transporter gene promoter polymorphism (5-HTTLPR) association with selective serotonin reuptake inhibitor efficacy in depressed patients. Mol Psychiatry 2007; 12: 247-257.

Soto-Ramirez N, Arshad SH, Holloway JW, Zhang H, Schauberger E, Ewart S, Patil V, Karmaus W. The interaction of genetic variants and DNA methylation of the interleukin-4 receptor gene increase the risk of asthma at age 18 years. Clin Epigenetics 2013; 5: 1.

Stockmeier CA. Involvement of serotonin in depression: evidence from postmortem and 
imaging studies of serotonin receptors and the serotonin transporter. $\mathrm{J}$ Psychiatr Res 2003; 37: 357-373.

Stranger BE, Nica AC, Forrest MS, Dimas A, Bird CP, Beazley C, Ingle CE, Dunning M, Flicek P, Koller D, Montgomery S, Tavare S, Deloukas P, Dermitzakis ET. Population genomics of human gene expression. Nat Genet 2007; 39: 1217-1224. Sullivan PF, Neale MC, Kendler KS. Genetic epidemiology of major depression: review and meta-analysis. Am J Psychiatry 2000; 157: 1552-1562.

Tunnard C, Rane LJ, Wooderson SC, Markopoulou K, Poon L, Fekadu A, Juruena M, Cleare AJ. The impact of childhood adversity on suicidality and clinical course in treatment-resistant depression. J Affect Disord 2013;

Ushijima T. Detection and interpretation of altered methylation patterns in cancer cells. Nat Rev Cancer 2005; 5: 223-231.

Vos T, Flaxman AD, Naghavi M, Lozano R, Michaud C, Ezzati M, Shibuya K, Salomon JA, Abdalla S, Aboyans V, Abraham J, Ackerman I, Aggarwal R, Ahn SY, Ali MK, Alvarado M, Anderson HR, Anderson LM, Andrews KG, Atkinson C, Baddour LM, Bahalim AN, Barker-Collo S, Barrero LH, Bartels DH, Basanez MG, Baxter A, Bell ML, Benjamin EJ, Bennett D, Bernabe E, Bhalla K, Bhandari B, Bikbov B, Bin Abdulhak A, Birbeck G, Black JA, Blencowe H, Blore JD, Blyth F, Bolliger I, Bonaventure A, Boufous S, Bourne R, Boussinesq M, Braithwaite T, Brayne C, Bridgett L, Brooker S, Brooks P, Brugha TS, Bryan-Hancock C, Bucello C, Buchbinder R, Buckle G, Budke CM, Burch M, Burney P, Burstein R, Calabria B, Campbell B, Canter CE, Carabin H, Carapetis J, Carmona L, Cella C, Charlson F, Chen H, Cheng AT, Chou D, Chugh SS, Coffeng LE, Colan SD, Colquhoun S, Colson KE, Condon J, Connor MD, Cooper LT, Corriere M, 
Cortinovis M, de Vaccaro KC, Couser W, Cowie BC, Criqui MH, Cross M, Dabhadkar KC, Dahiya M, Dahodwala N, Damsere-Derry J, Danaei G, Davis A, De Leo D, Degenhardt L, Dellavalle R, Delossantos A, Denenberg J, Derrett S, Des Jarlais DC, Dharmaratne SD, Dherani M, et al. Years lived with disability (YLDs) for 1160 sequelae of 289 diseases and injuries 1990-2010: a systematic analysis for the Global Burden of Disease Study 2010. Lancet 2012; 380: 2163-2196.

Wang D, Szyf M, Benkelfat C, Provencal N, Turecki G, Caramaschi D, Cote SM, Vitaro F, Tremblay RE, Booij L. Peripheral SLC6A4 DNA methylation is associated with in vivo measures of human brain serotonin synthesis and childhood physical aggression. PLoS One 2012; 7: e39501.

Weaver IC, Cervoni N, Champagne FA, D'Alessio AC, Sharma S, Seckl JR, Dymov S, Szyf M, Meaney MJ. Epigenetic programming by maternal behavior. Nat Neurosci 2004; 7: 847-854.

World Health Organization (WHO). Depression. In: Media centre 2012; http://www.who.int/mediacentre/factsheets/fs269/en/: Accessed 15 Mar 2013.

Widom CS, DuMont K, Czaja SJ. A prospective investigation of major depressive disorder and comorbidity in abused and neglected children grown up. Arch Gen Psychiatry 2007; 64: 49-56.

Zhang TY, Labonte B, Wen XL, Turecki G, Meaney MJ. Epigenetic mechanisms for the early environmental regulation of hippocampal glucocorticoid receptor gene expression in rodents and humans. Neuropsychopharmacology 2013; 38: $111-123$. 


\section{Contributors}

Conceived and designed the experiments: Satoshi Okada, Shigeru Morinobu, Manabu Fuchikami, Masahiro Segawa.

Performed the experiments: Satoshi Okada, Kana Yokomaku, Tsutomu Kataoka. Analyzed the data: Satoshi Okada, Shigeru Morinobu, Manabu Fuchikami. Wrote the paper: Satoshi Okada, Shigeru Morinobu, Manabu Fuchikami. Contributed to collecting materials: Yasumasa Okamoto, Shigeto Yamawaki, Ichiro Kusumi, Tsukasa Koyama, Kounosuke Tsuchiyama, Takeshi Terao, Masaru Mimura.

Everyone who is listed as an author have made a substantial, direct, intellectual contribution to the work. All authors have participated in writing the manuscript by reviewing drafts and approving the final version. 


\section{Role of Funding Source}

Experimental research by the author is supported by public funds from the Ministry of Education, Culture, Sports, Science and Technology of Japan, and Japan Science and Technology (JST), as stated in acknowledgements. 
Fig. 1 Schematic representation of the SLC6A4 gene promoter region

Two primers covering the SLC6A4 transcription start site, exon I, part of intron I and the $\mathrm{CpG}$ island were used for the DNA methylation study. The target region consists of 862 bp including 81 CpGs. 5HTTLPR is located 960 bp upstream of the $\mathrm{CpG}$ island.

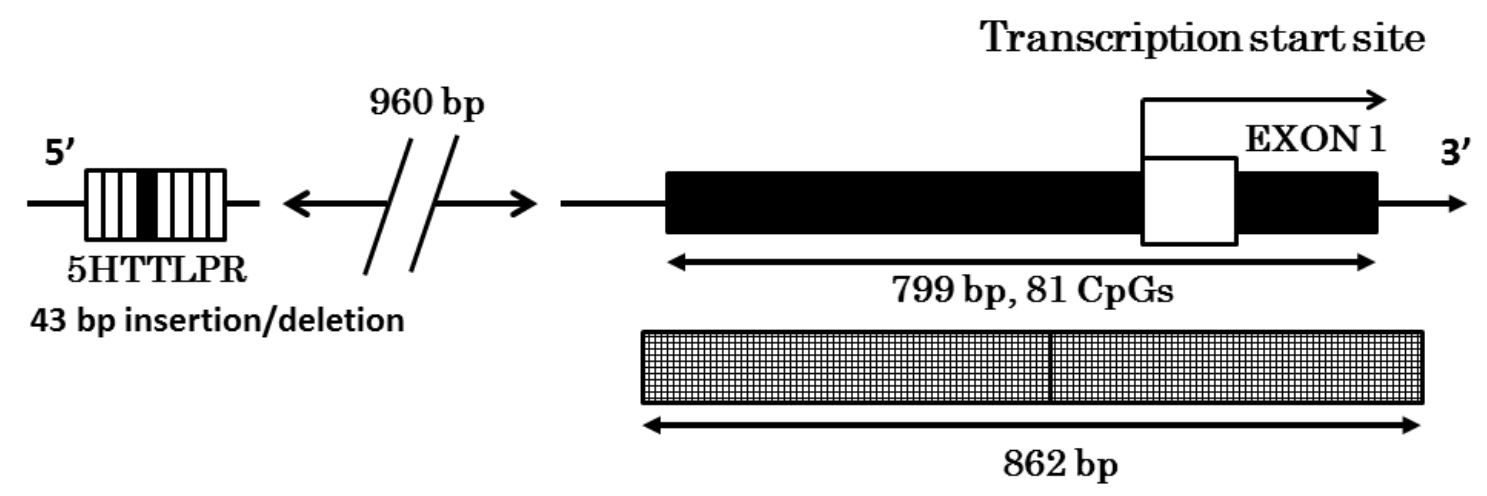


Table 1. Demographic characteristics of subjects.

Demographic characteristics of subjects

\begin{tabular}{|c|c|c|c|c|c|c|}
\hline \multirow[t]{2}{*}{ Group } & \multirow[t]{2}{*}{$\begin{array}{l}\text { Age (Years) } \\
\text { (Mean } \pm \text { S.D.) }\end{array}$} & \multirow[t]{2}{*}{ Genotype } & \multicolumn{2}{|c|}{$\begin{array}{l}\text { HAM-D score } \\
\text { (Mean } \pm \text { S.D.) }\end{array}$} & \multirow[t]{2}{*}{$\begin{array}{c}\text { ETI score } \\
\text { (Mean } \pm \text { S.D.) }\end{array}$} & \multirow[t]{2}{*}{$\begin{array}{c}\text { IR (\%) } \\
\text { (Mean } \pm \text { S.D.) }\end{array}$} \\
\hline & & & Before & After 6 weeks & & \\
\hline $\begin{array}{c}\text { Control } \\
(\mathrm{N}=50,27 \mathrm{M} / 23 \mathrm{~F})\end{array}$ & $40.3 \pm 10.5$ & LL:2, SL:16, SS:32 & & & & \\
\hline $\begin{array}{l}\text { Major depression } \\
(\mathrm{N}=50,27 \mathrm{M} / 23 \mathrm{~F})\end{array}$ & $40.3 \pm 10.3$ & SL:16, SS:34 & $20.6 \pm 4.8$ & $8.1 \pm 6.6$ & $5.0 \pm 3.8$ & $60.2 \pm 31.3$ \\
\hline
\end{tabular}

M : males, F : females, ETI : Early Trauma Inventory, IR : improvement ratio, HAM-D : Hamilton Rating Scale for Depression. 
Table 2

The DNA methylation rates of each CpG unit at the CpG island of the SLC6A4 gene in healthy controls and patients with major depression.

\begin{tabular}{|c|c|c|c|c|c|}
\hline & \multirow{2}{*}{$\begin{array}{c}\text { Control } \\
\text { Rate }(\%) \\
\text { (Mean } \pm \text { S.E.M) }\end{array}$} & \multirow{2}{*}{$\begin{array}{c}\text { Depression } \\
\text { Rate }(\%) \\
\text { (Mean } \pm \text { S.E.M) }\end{array}$} & \multirow{2}{*}{$\begin{array}{c}\text { Depression(6W) } \\
\text { Rate }(\%) \\
(\text { Mean } \pm \text { S.E.M) }\end{array}$} & \multicolumn{2}{|c|}{ Statistical analysis } \\
\hline & & & & $\begin{array}{c}\text { Con vs Dep } \\
\text { (P-value) }\end{array}$ & $\begin{array}{c}\text { Dep vs D6W } \\
\text { (P-value) }\end{array}$ \\
\hline CpG 1 & $7.7 \pm 0.4$ & $8.4 \pm 0.4$ & $7.7 \pm 0.5$ & 0.20 & 0.68 \\
\hline CpG 3 & $5.1 \pm 0.2$ & $4.9 \pm 0.3$ & $6.1 \pm 0.3$ & 0.24 & $0.0004 *$ \\
\hline CpG 4 & $4.1 \pm 0.3$ & $4.0 \pm 0.3$ & $5.7 \pm 0.6$ & 0.84 & 0.03 \\
\hline CpG 10 & $4.1 \pm 0.3$ & $4.0 \pm 0.3$ & $5.7 \pm 0.6$ & 0.84 & 0.03 \\
\hline CpG 11 & $24.2 \pm 0.7$ & $24.0 \pm 0.6$ & $25.2 \pm 0.8$ & 0.50 & 0.95 \\
\hline CpG 24,25 & $5.7 \pm 0.2$ & $5.2 \pm 0.2$ & $4.6 \pm 0.2$ & 0.09 & 0.08 \\
\hline CpG 26,27,28 & $3.8 \pm 0.2$ & $3.7 \pm 0.2$ & $3.6 \pm 0.2$ & 0.79 & 0.28 \\
\hline CpG 29 & $4.6 \pm 0.4$ & $4.3 \pm 0.7$ & $6.3 \pm 1.3$ & 0.23 & 0.69 \\
\hline CpG 30 & $5.5 \pm 0.9$ & $5.9 \pm 1.1$ & $11.8 \pm 3.2$ & 0.58 & 0.17 \\
\hline CpG 31,32 & $1.6 \pm 0.2$ & $1.3 \pm 0.1$ & $2.0 \pm 0.3$ & 0.69 & 0.28 \\
\hline CpG 33,34,35,36 & $4.3 \pm 0.2$ & $3.9 \pm 0.2$ & $4.1 \pm 0.2$ & 0.10 & 0.29 \\
\hline CpG 37 & $6.6 \pm 0.2$ & $5.9 \pm 0.3$ & $5.5 \pm 0.3$ & 0.007 & 0.94 \\
\hline CpG 39,40 & $4.4 \pm 0.1$ & $4.2 \pm 0.2$ & $3.8 \pm 0.2$ & 0.21 & 0.10 \\
\hline CpG 41,42 & $7.3 \pm 0.4$ & $7.3 \pm 0.4$ & $8.0 \pm 0.6$ & 0.73 & 0.44 \\
\hline CpG 49,50,51,52 & $6.0 \pm 0.4$ & $5.8 \pm 0.3$ & $6.5 \pm 0.5$ & 0.72 & 0.13 \\
\hline CpG 55 & $14.5 \pm 0.3$ & $15.0 \pm 0.3$ & $15.2 \pm 0.4$ & 0.24 & 0.34 \\
\hline CpG 56 & $1.3 \pm 0.2$ & $1.1 \pm 0.2$ & $1.1 \pm 0.3$ & 0.51 & 0.77 \\
\hline CpG 57,58 & $20.4 \pm 0.5$ & $20.8 \pm 0.4$ & $21.5 \pm 0.5$ & 0.43 & 0.23 \\
\hline CpG 62 & $19.9 \pm 1.0$ & $20.3 \pm 1.0$ & $19.2 \pm 1.6$ & 0.59 & 0.44 \\
\hline CpG 65,66 & $20.4 \pm 0.5$ & $20.8 \pm 0.4$ & $21.5 \pm 0.5$ & 0.43 & 0.23 \\
\hline CpG 67,68 & $24.1 \pm 0.7$ & $23.2 \pm 0.8$ & $23.8 \pm 0.6$ & 0.61 & 0.67 \\
\hline CpG 70 & $33.8 \pm 1.9$ & $35.2 \pm 2.2$ & $34.7 \pm 2.7$ & 0.92 & 0.18 \\
\hline CpG 71,72,73 & $13.8 \pm 0.5$ & $14.6 \pm 0.4$ & $13.5 \pm 0.4$ & 0.29 & 0.16 \\
\hline CpG 74 & $15.4 \pm 0.7$ & $16.1 \pm 0.7$ & $15.6 \pm 0.9$ & 0.63 & 0.99 \\
\hline CpG 75 & $49.1 \pm 1.8$ & $51.1 \pm 1.8$ & $49.3 \pm 2.6$ & 0.56 & 0.20 \\
\hline CpG 76 & $15.9 \pm 0.5$ & $16.3 \pm 0.7$ & $16.6 \pm 0.7$ & 0.91 & 0.56 \\
\hline CpG 78 & $3.3 \pm 0.3$ & $3.7 \pm 0.4$ & $2.8 \pm 0.3$ & 0.80 & 0.50 \\
\hline CpG 79 & $9.8 \pm 0.8$ & $11.2 \pm 0.9$ & $9.8 \pm 0.8$ & 0.14 & 0.59 \\
\hline CpG 80,81 & $32.3 \pm 0.7$ & $33.6 \pm 0.8$ & $34.1 \pm 1.0$ & 0.38 & 0.99 \\
\hline
\end{tabular}

Control(CON) : Healty controls, Depression (DEP) : Unmedicated patients with MD, Depression6W (D6W) : Medicated patients with MD Statistical analysis : Mann-Whitney $U$ test (Healthy subjects and unmedicated patients with MD)

Wilcoxon ranked signed test (Unmedicated patients with MD and medicated patients with MD)

The mean methylation rate and $P$-value are shown.

The asterisks $(*)$ behind of scores indicate statistically significant p-values. Significance was set at $\mathbf{P}<0.0017$. 
Table 3

Relationships of the DNA methylation rates at the CpG island of the SLC6A4 gene with clinical characteristics in patients with major depression.

\begin{tabular}{|c|c|c|c|}
\hline & \multicolumn{3}{|c|}{ Correlation coefficient } \\
\hline & HAMD & ETI & IR \\
\hline CpG 1 & 0.26 & -0.15 & 0.08 \\
\hline CpG 3 & -0.03 & $-0.32 *$ & $0.36 *$ \\
\hline CpG 4 & 0.02 & 0.008 & -0.01 \\
\hline CpG 10 & 0.02 & 0.008 & -0.01 \\
\hline CpG 11 & -0.24 & 0.25 & -0.06 \\
\hline CpG 24,25 & -0.09 & 0.08 & -0.008 \\
\hline CpG 26,27,28 & 0.17 & 0.05 & -0.004 \\
\hline CpG 29 & 0.11 & -0.01 & -0.12 \\
\hline CpG 30 & -0.16 & -0.12 & 0.15 \\
\hline CpG 31,32 & -0.17 & 0.09 & -0.10 \\
\hline CpG $\mathbf{3 3 , 3 4 , 3 5 , 3 6}$ & 0.03 & 0.14 & -0.17 \\
\hline CpG 37 & 0.06 & -0.04 & 0.18 \\
\hline CpG 39,40 & -0.23 & 0.06 & 0.11 \\
\hline CpG 41,42 & -0.21 & -0.19 & -0.03 \\
\hline CpG 49,50,51,52 & -0.07 & 0.28 & 0.07 \\
\hline CpG 55 & 0.13 & 0.19 & 0.05 \\
\hline CpG 56 & -0.26 & 0.18 & 0.04 \\
\hline CpG 57,58 & 0.19 & 0.03 & 0.12 \\
\hline CpG 62 & 0.24 & 0.10 & 0.05 \\
\hline CpG 65,66 & 0.19 & 0.03 & 0.12 \\
\hline CpG 67,68 & 0.15 & -0.003 & 0.03 \\
\hline CPG 70 & -0.15 & -0.17 & -0.10 \\
\hline CpG 71,72,73 & 0.04 & 0.05 & -0.14 \\
\hline CpG 74 & 0.16 & 0.19 & 0.13 \\
\hline CpG 75 & -0.07 & -0.06 & -0.23 \\
\hline CpG 76 & $0.30^{*}$ & $0.32 *$ & -0.07 \\
\hline CpG 78 & 0.03 & 0.17 & 0.02 \\
\hline CPG 79 & 0.21 & 0.06 & -0.20 \\
\hline CpG 80,81 & 0.13 & 0.11 & 0.14 \\
\hline
\end{tabular}

ETI : Early Trauma Inventory, IR : improvement ratio, HAM-D : Hamilton Rating Scale for Depression. Statistical analysis : Spearmann rank correlation test.

The correlations between the methylation rates and total HAMD scores, total ETI scores and IR are shown.

The asterisks $\left(^{*}\right)$ behind of several correlations indicate significantly correlations

which have statistically significant p-values in subsequent analyses by t-test.

Significance was set at $P<0.05$. 